\title{
STUDIES ON THE TOXICITY OF COAL-TAR DYES III. REASON OF ACUTE TOXICITY TO FISH CAUSED BY COAL-TAR DYES AND THEIR INDUSTRIAL EFFLUENTS
}

\author{
Yasuhide TonogaI, Yoshio Ito, Masahiro IwaIdA, \\ Masatomo TATI*, Youki OSE and Mikio HoRI** \\ National Institute of Hygienic Sciences, Osaka Branch \\ 1-1, Hoenzaka, Higashi-ku, Osaka 540, Japan \\ * Gifu University, 3-1, Monzen-cho, Naka, Kakamigahara, Gifu 504, Japan \\ ${ }^{* *}$ Gifu College of Pharmacy, 5-6-1, Mitahora-higashi, Gifu 502, Japan
}

Accepted January 18, 1980

\begin{abstract}
Reason of acute toxicity to fish caused by coal-tar dyes and their industrial effluents were studied from the three points of view.

1) Partition coefficient (n-octanol/water) was determined on several coal-tar dyes, and it was found that the larger the ratio was, the stronger was toxicity to fish. 2) As a result of determination about existent form of xanthene dyes under photoirradiation, it was clarified that dyes in solution were in the form of excited triplet state and halogen in dye molecule was liberated in free form.

3) When coal-tar dyes were treated with sodium hypochlorite, harmful chloroform was detected from dye solution. Chloroform and its homologous compounds showed the low TLm value and had the serious effect on fish.

Key words: partition coefficient, survival test, TLm value, photo-irradiation, excited triplet state, radical scavenger, ESR spectrum, chlorination, waste water, potentiometry, organohalide compound
\end{abstract}

\section{INTRODUCTION}

In the previous papers (Tonogai et al., 1978), it was pointed out by the authors that xanthene dyes were selectively adsorbed on the gill leading to the death of fish by anoxemia. Sugiura et al. (1978) studied on the accumulation of mono-, di-and tetrachlorobiphenyls as well as di-, tri- and tetrabromobiphenyls in the Himedaka (Oryzias Latipes) and found that the accumulation were proportional to the partition coefficient of the substances between n-octanol and water. Since it was assumed in our experiment (Tonogai et al., 1979A) that the death of fish was due to the inhibition of gill function with dyes, it was attempted here to examine the partition coefficient of several dyes between $n$ octanol and water to find out a correlation between toxicity and partition coefficient.

Besides, it was already clarified in the previous papers (Tonogai et al.,1979 ${ }^{\mathrm{B}}$ ) too, that

連絡先：画540 大阪市東区法円坂町 1-1 国立衛生試験所・大阪支所 外 海 泰 秀 
the increases in number of died fish by photo-irradiation of xanthene dyes were due to the liberation of halogens from the dye and that the status of existence of the halogen in Concerning affected on the degree of the toxicity extremely. It was attempted in this report to pursue mechanism for dehalogenation of dye under photo-irradiation and the state of liberated halogen in the solution.

Concerning as the dyes which had halogens in their structures, the liberated halogen by photo-irradiation might be toxic to fish; while even in case of dyes without halogens in the structures, there is a possibility of formation of a harmful organohalide compound when the dye in the industrial effluent was treated with chlorinating agent for the purpose of decolorization.

Symons et al. (1974) reported that trace amounts of chloroform and other organohalides were detected in tap water and they presumed that organohalides could be formed when the water source was chlorinated, provoking a serious environmental problem. Murphy et al. (1975) and Larson et al. (1979) repoted formation of chloroform naturally from phenol and benzoic acid derivatives by chlorination with aqueous hypochlorite.

In this paper the formation of chloroform was pursued when several dyes were treated with sodium hypochlorite in the treatment of industrial waste water.

\section{METHODS}

1. Materials and equipments

1) Coal-tar dyes: The reference standards of the National Institute of Hygienic Sciences and commercial reagent (G. R.)

2) n-Octanol and chloroform: Tokyo Kasei Kogyo Co. Ltd. (G. R.)

3) Mono- and diiodocyclohexane: E. Merck \& Co., Inc. (G. R.)

4) Sodium hypochlorite: $5 \%$ solution (antiformin) from Nakarai Co. Ltd. (G. R.) Available chlorine was checked before use according to the procedure defined by the Japanese Industrial Standards Committee (1974).

5) Himedaka (Oryzias latipes): The same age of fish (about $2 \mathrm{~cm}$ long, weight ca. 0. $2 \mathrm{~g}$ ) were chosen and acclimated for 10 days in the tap water before experiment.

6) Spectrophotometer: Type 556, Hitachi Co. Ltd.

7) Gas chromatograph: Yanaco G-80 with flame ionization and electron capture detection systems, Yanagimoto Mfctg. Co. Ltd,, Kyoto.

8) Electron spin resonance (ESR) spectrometer: Jeol 3B-X, Nihon Denshi Co. Ltd.

9) Potentiograph: Type E336A, Metrohm, Helisau.

10) Gas chromatograph-mass spectrometer (GC-MS): JGC-20KP and JMS-D300, Nihon Denshi Co. Ltd.

2. Test methods

1) Determination of partition coefficient ( $\mathrm{n}$-octanol/water) of dye : $100 \mathrm{ml}$ of a dye solution $(3 \mathrm{mg} / \mathrm{ml}$ ) was adjusted to $\mathrm{pH} 7.0$ with $\mathrm{NaOH}$ or $\mathrm{HCI}$, was shaken for 10 min with $100 \mathrm{ml}$ of n-octanol at $25^{\circ} \mathrm{C}$ by mechanical shaker, and then stood for 
$1 \mathrm{hr}$, and the absorbance of dye in aqueous layer was determined at the $\lambda \max$ of each dye. Partition is expressed by the following formula (Stary, 1964).

Partition coefficient $=\frac{C_{o r g}}{C_{a g}}=\frac{\gamma_{a q}}{\gamma_{o r g}} \exp \left(-\left[\mu_{o r g}-\mu_{a q}\right] / R T\right)$ where $\mathrm{C}_{\text {org }}$ and $\mathrm{C}_{\mathrm{aq}}$ denote the concentration of the distributed compounds, $\gamma_{\mathrm{org}}$ and $\gamma_{\mathrm{aq}}$ represent the activity coefficients, and $\mu_{\mathrm{orq}}$ and $\mu_{\mathrm{aq}}$ represent the standard chemical potentials of the solute in the organic and aqueous phases, respectively.

2) Survival test of fish : In one liter solution of $\mathrm{pH} 7.0$ containing $3,000 \mathrm{mg} / \mathrm{L}$ of a dye to be tested, ten fish were kept in the tank without direct sunlight for 48 hours and the survival rate was determined. Water temperature was $25^{\circ} \mathrm{C}$.

3) TLm test: TLm was determined according to the procedure in JIS K0102 (Japanese Industrial Standards Committee, 1971). Each dye was tested at 4-6 steps of concentration utlizing ten fish per one group and the number of survivals was counted after 24 and 48 hours. Lethal concentration of 50\% fish wạs estimated.

4) Survival test of fish under photo-irradiation:Ten fish were kept into one liter of dye solution held in one liter beaker containing $200 \mathrm{mg} / \mathrm{L}$ of Phloxine $(\mathrm{pH} \mathrm{6.8)}$ and $100 \mathrm{mg} / \mathrm{L}$ of Rose Bengale ( $\mathrm{pH} 6.9$ ), then the contents were irradiated with $150 \mathrm{~W}$ white light from above $20 \mathrm{~cm}$ of the water level. The survival tests were carried out both with and without blowing of oxygen gas $(0.1 \mathrm{liter} / \mathrm{min})$ into the dye solution, and control was carried out without dye.

5) ESR spectra were recorded at room temperature with a $100 \mathrm{KHz}$ field modulation.

6) Identification of halogen liberated from dye under photo-irradiation: $2 \mathrm{mM}$ of cyclohexene was added to $500 \mathrm{ml}$ of Rose Bengale solution $(2 \mathrm{mM})$ and halogenated cyclohexane derivatives formed under photo-irradiated condition as the same as 2-3) were identified by gas chromatography after extraction with $50 \mathrm{ml}$ of ether.

7) Determination of iodine liberated from dye under photo-irradiation: $500 \mathrm{ml}$ of Rose Bengale solution ( $2 \mathrm{mM}$ ) was photo-irradiated under the condition as the same as 2-3). Iodine liberated in the reaction mixture was titrated with $0.1 \mathrm{~N}$ silver nitrate with the aid of potentiograph (Motonaka, 1979).

8) Identification and determination of chloroform after chlorination of dye: An aliquot quantity of sodium hypochlorite was added to $10 \mathrm{ml}$ of dye solution $(2 \mathrm{mM})$ and shaken for a definite time at $25^{\circ} \mathrm{C}$. Then, chloroform formed in the reaction mixture was identified by GC-MS and the amount of chloroform was determined by GC.

\section{RESULTS AND DISCUSSION}

1. Correlation between toxicity to fish and partition coefficient of dyes

Correlation between the partition coefficient and survial rate of fish about several dyes 


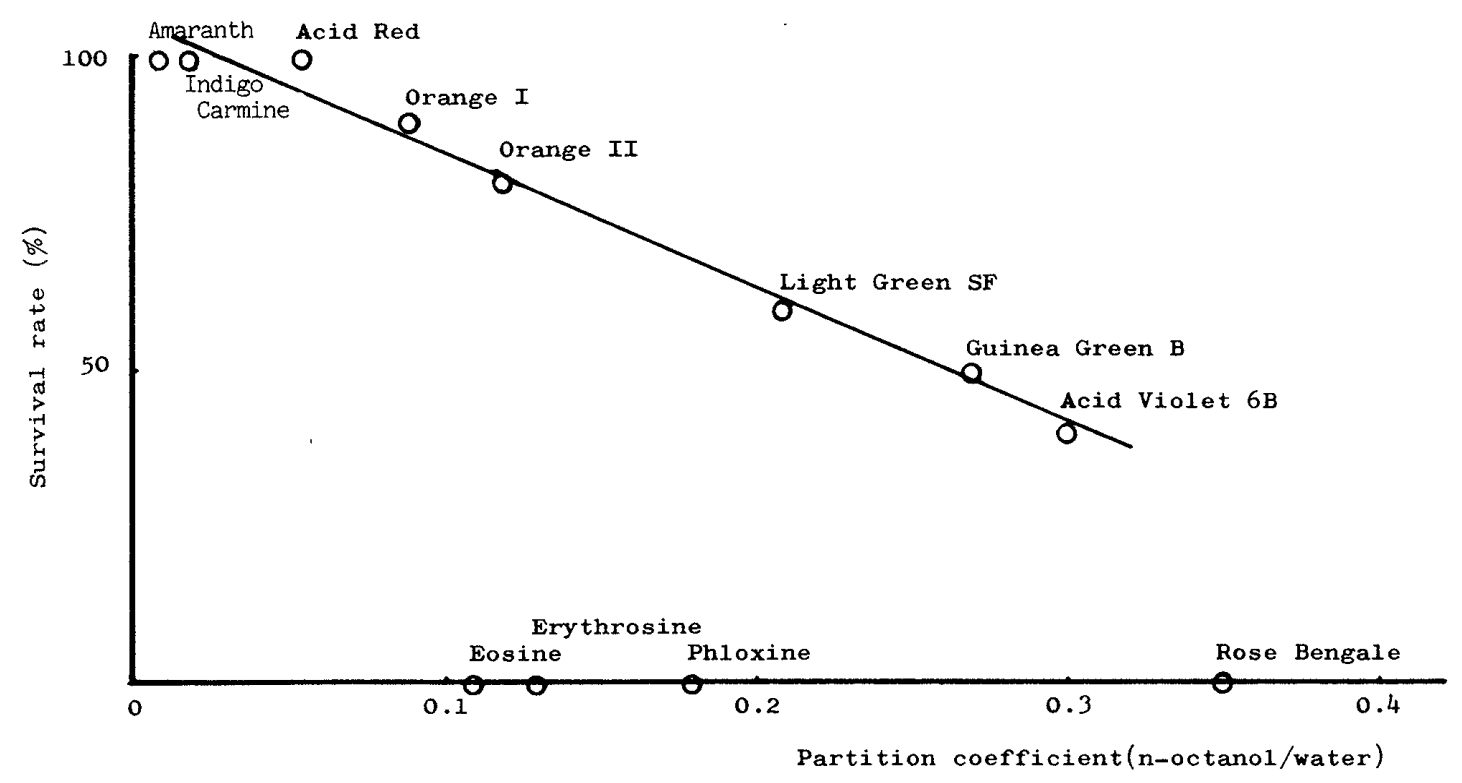

Fig. 1 Correlation between partition coefficient of dye and survival rate of fish in dye solution

Note 1) 3,000 mg of dye was used and survival rate was counted after 48 hrs at $25^{\circ} \mathrm{C}$.

Note 2) Partition coefficient of dye between n-octanol and water was determined by OD in water layer after shaking equal volume of the two solvents.

were shown in Fig. 1.

Concerning the same content of Amaranth, Indigo Carmine, Acid Red, Orange I, Orange II, Light Green SF, Guinea Green B and Acid Violet 6B, a following relationship was observed; the larger the partition coefficient was, the lower was the survival rate of fish.

The partition coefficient and TLm value were determined about Martius Yellow (C. I. 10315) and Naphthol Yellows (C. I. 10316).

Martius Yellow has a relatively large partition coefficient (2.50), and its toxicity to fish is very high, TLm value being less than $1 \mathrm{mg} / 1$. Contrary to this, Naphthol Yellow S has very small partition coefficient $(0.00)$ and its toxicity to fish is very low, TLm value being more than $1,000 \mathrm{mg} / \mathrm{L}$. The increases in number of sulfonate group makes the dye hydrophilic and lower the partition coefficient, which results in the less absorption of the dye in the fish body. This relation was in conform to all kinds of dyes in Fig. 1.

On the other hand, concerning xanthene dyes (Eosine, Erythrosine, Phloxine and Rose Bengale), though their partition coefficients are the same as other dyes (0.11-0135), the survival rate is ultimately low. It was presumed that toxicity of xanthene dyes was derived from another reason in their structures. 
2. Investigation on the mechanism for dehalogenation of xanthene dyes

1) Existent state of dye under photo-irradiation

Himedaka were kept in $200 \mathrm{mg} / \mathrm{L}$ solution of Phloxine and $100 \mathrm{mg} / \mathrm{L}$ solution of Rose Bengale (these concentrations are equivalent to TLm values of $48 \mathrm{hrs}$ ), and time course of survival rate was determined under photo-irradiation (the temperature of water changed from $25^{\circ} \mathrm{C}$ to $28^{\circ} \mathrm{C}$ ).

These results are shown in Fig. 2.

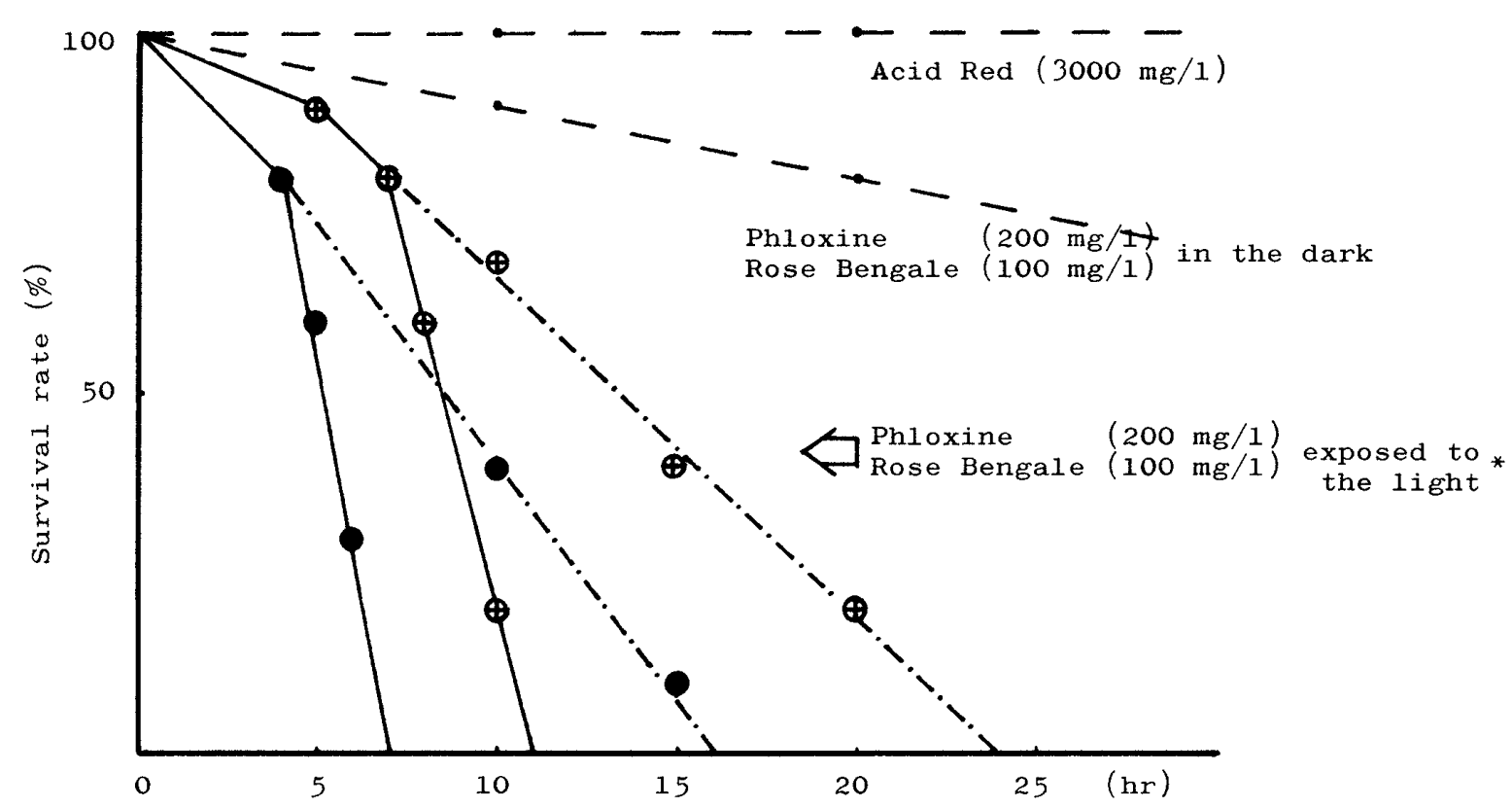

Fig. 2 Effect of photo-irradiation on survival test of fish in Phloxine and Rose Bengale solutions

*Ten fish of Himedaka, kept in IL of dye solution, filled in IL beaker, were irradiated with $150 \mathrm{~W}$ white light from above $20 \mathrm{~cm}$ of the water level.
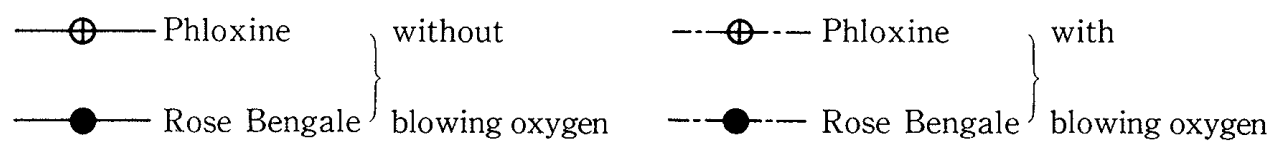

Number of dead fish increased remarkably by irradiation of dyes and all the fish died after $7-11 \mathrm{hrs}$. While under the bubbling of oxygen gas, the time of death was delayed and all the fish died after 16-24 hrs.

In order to confirm the existent form of excited dyes, ESR spectra were determined on photo-irradiated fluorescein sodium and Rose Bengale solutions. The spectra are shown in Chart 1. 

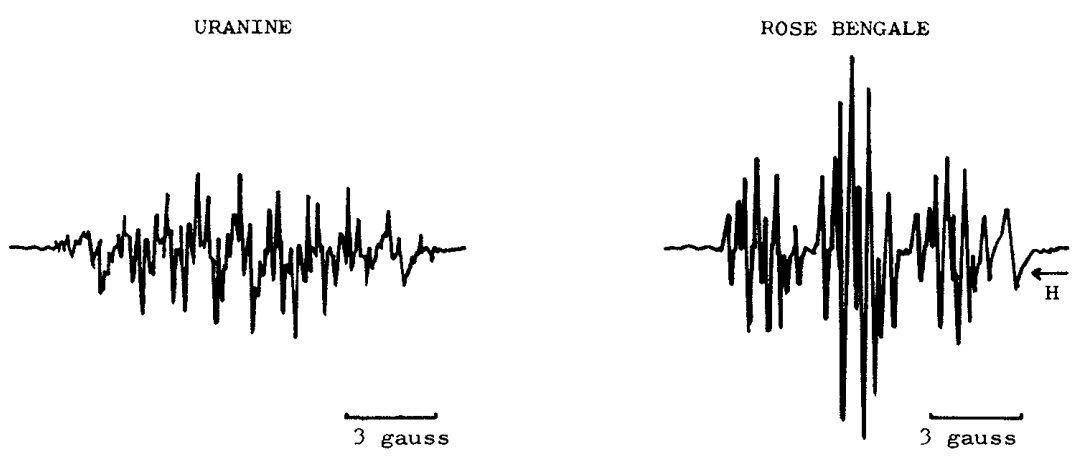

Chart 1 The ESR spectra of photo-irradiated Uranine and Rose Bengale solutions

The ESR spectrum of irradiated Rose Bengale consists of three groups of lines with the intensity ratio of $1: 2: 1$ and with the coupling constant of 3.20 gauss. The ESR spectrum for Uranine is more complicated than that of Rose Bengale. It is explained from the fact that four iodine and four chlorine atoms are replaced by hydrogen atoms for Uranine. These results are evidence for the conclusion that the products are radical form.

From these results it is supposed that xanthene dyes became excited state under photoirradiation and liberated halogen from the mother compound. But through bubbling of oxygen gas as radical scavenger (Matsuura, 1970), energy of excited xanthene dyes were transfered to lower level, consequently the liberation of halogen was suppressed and the survival rate of fish was increased.

2) Existent state of halogen under photo-irradiation

In order to confirm the existent form of liberated halogen, cyclohexene was added to photo-irradiated Rose Bengale solution and the formed cyclohexane derivatives were identified by gas chromatography. The gas chromatogram is shown in Chart 2 .

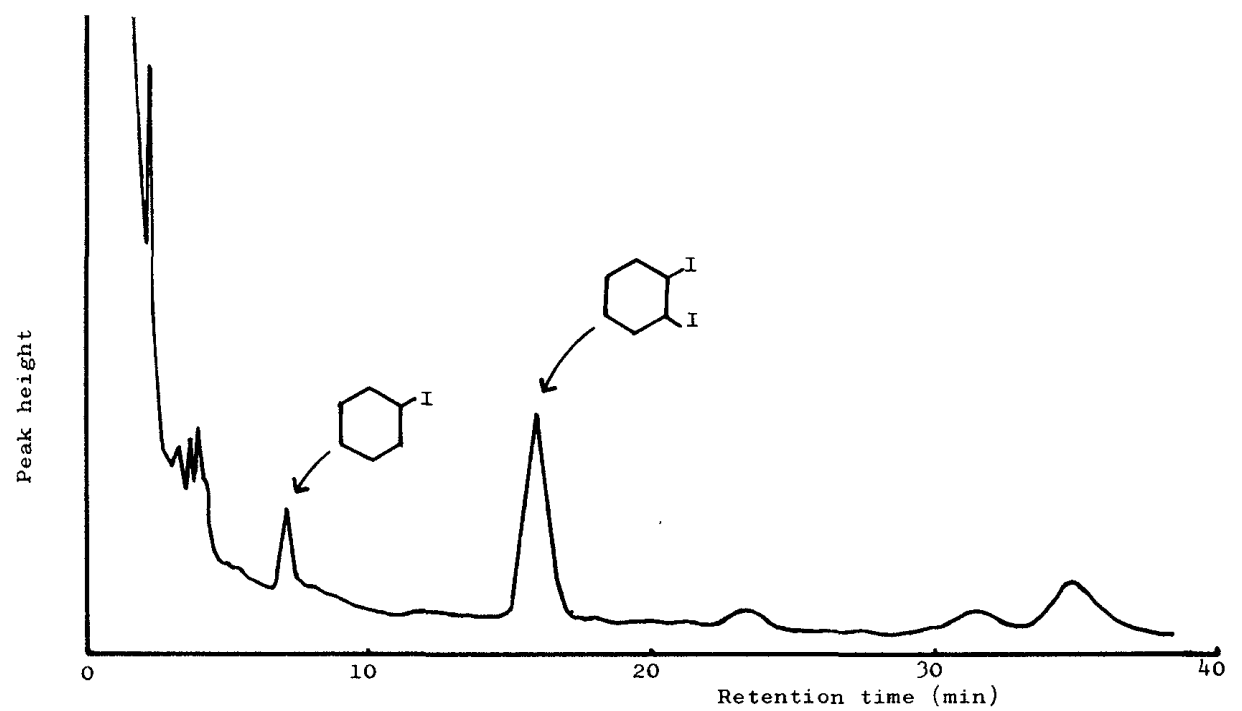

Chart 2 Gas chromatogram obtained from Photolysis of Rose Bengale and cyclohexene mixture

Column: 20\% PEG-400 on Chromosorb W $(60-80)$

Temperature : column- $90^{\circ} \mathrm{C}$, Injection $-150^{\circ} \mathrm{C}$

Flow rate: $\mathrm{N}_{2}-30 \mathrm{ml} / \mathrm{min}$, Air $-\mathrm{IL} / \mathrm{min}, \mathrm{H}_{2}-0.6 \mathrm{~kg} / \mathrm{cm}^{2}$ 
Main peaks appeared at the retention times of 7 and 16 minutes, and these peaks corresponded with those of mono- and diiodocyclohexane, respectively. This fact indicates that iodine was liberated in free form from dye and captured by cyclohexene under photo-irradiation. Chlorine derivatives of cyclohexane were not found, indicating that chlorine at 12,13,14 and 15 positions were not liberated from dye. From the fact, it is known that iodine in the dye is more labile than chlorine under photo-irradiation.

Amount of liberated iodine in irradiated dye solution without cyclohexene was determined by potentiography. The result is shown in Fig. 3 .

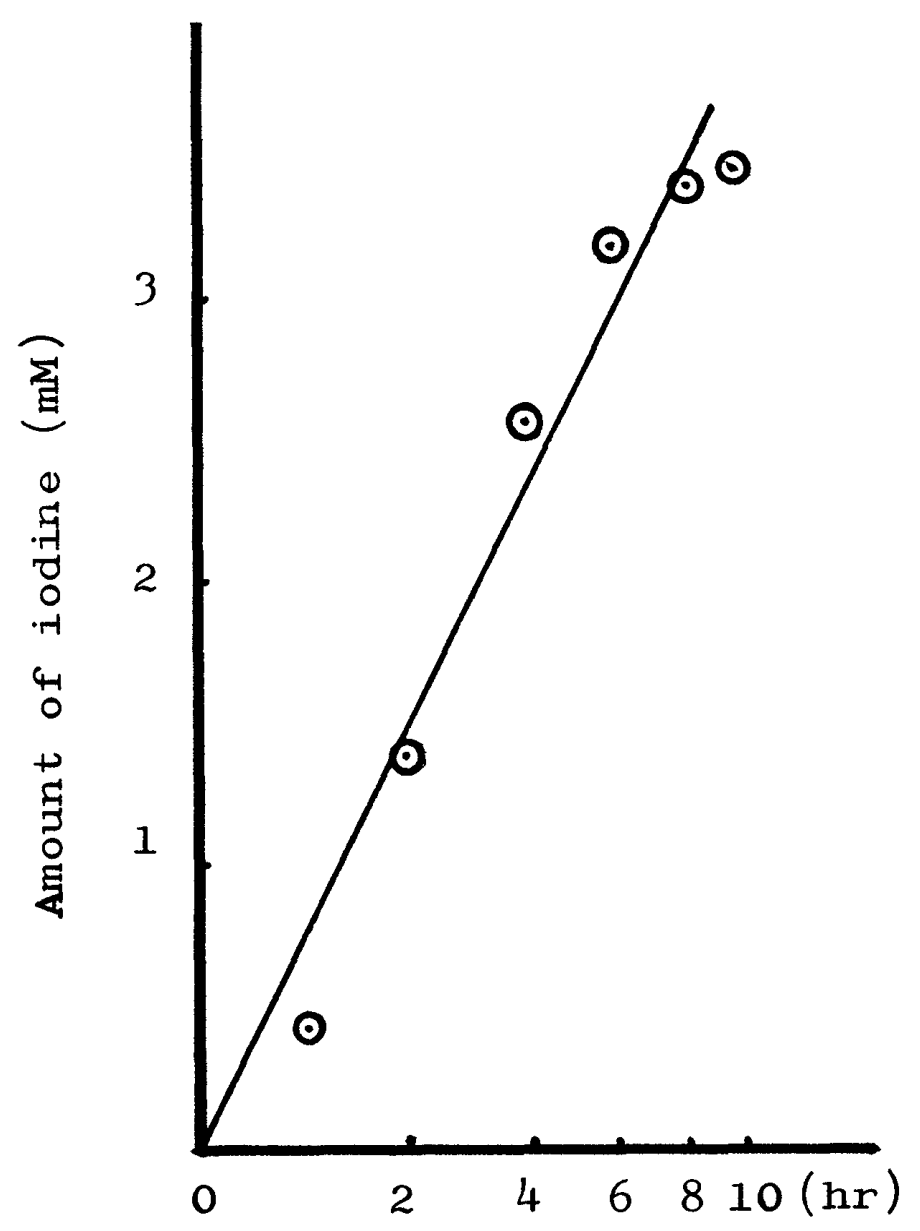

Fig. 3 Determination of iodine liberated from Rose Bengale by potentiometric titration

Note 1) Rose Bengale solution ( $2 \mathrm{mM})$ was photo-irradiated.

Note 2) Iodide-selective indicator electrode and saturated caromel reference electrode were used. 
It was found that chloroform might be formed when industrial effluents of dyes were treated with chlorinating agent in order to decolorize dyes. Formation of chloroform was dependent on concentration of chlorine and time of reaction. The results are shown in Fig. 5 .

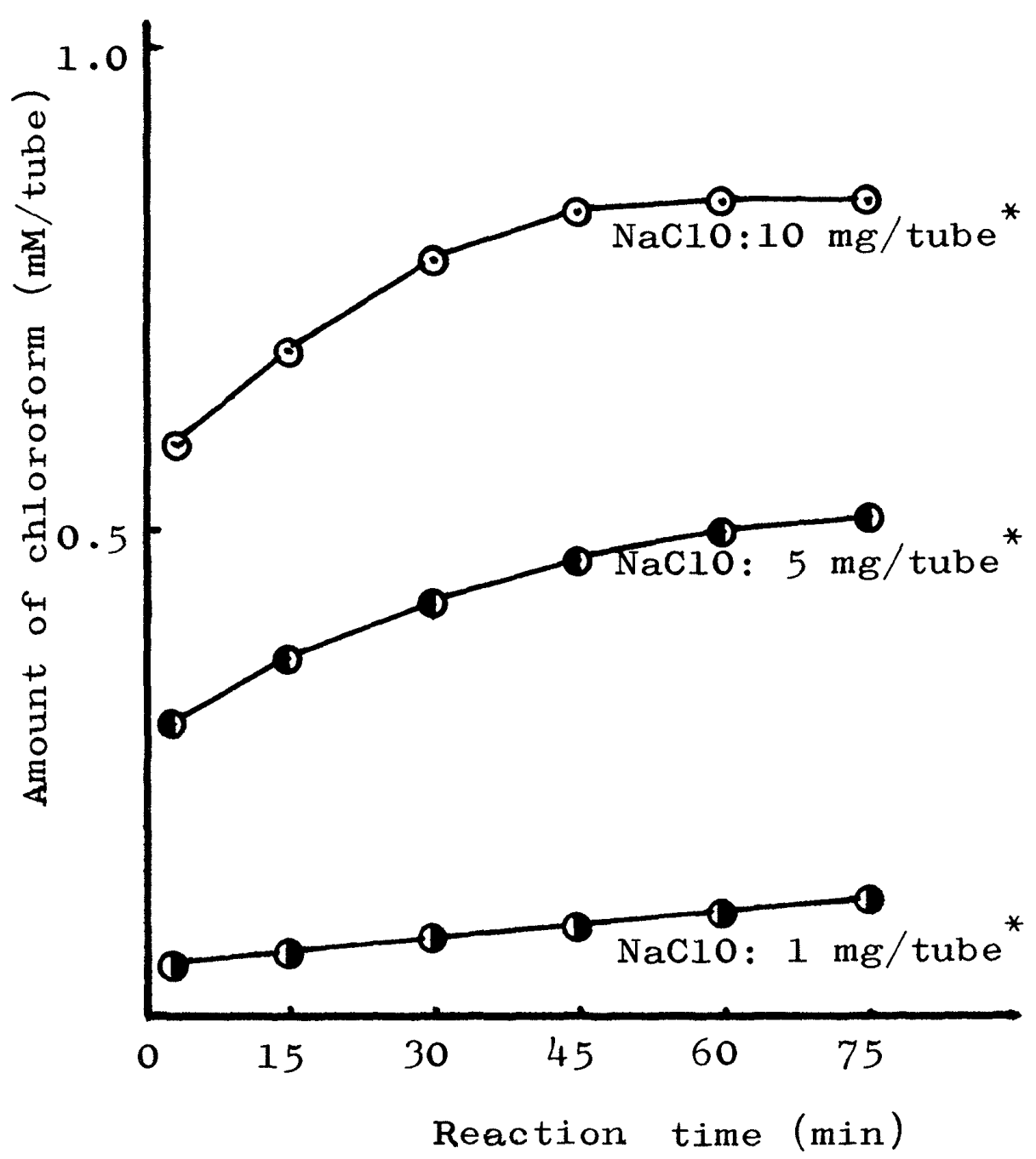

Fig. 5 Effects of conc. of sodium hypochlorite and of reaction time on the formation of chloroform after chlorination of dye *Sodium hypochlorite was added to New Coccine solution (2 $\mathrm{mM}$ ) and amount of chloroform was determined by gas chromatography (ECD)

When $10 \mathrm{mg}$ of sodium hypochlorite (ca. $10 \mathrm{mM}$ ) was added to $2 \mathrm{mM}$ of dye, it was observed that dye was decolored within $5 \mathrm{~min}$. and the color could not be redeveloped. It was assumed that the stronger the condition of chlorination was, the more was decomposition of dye accelerated and consequently organohalide compunds were formed. 
The amount of liberated iodine corresponded with the amount of deiodinated Rose Bengale (12, 13, 14, 15-tetrachlorofluorescein sodium), which had been determined by high performance liquid chromatography in our previous papers (Tonogai et al., 1979).

3. Formation of organohalide compound from dye solution

After shaking dye solution with sodium hypochlorite, the formation of organohalide compounds in reaction mixture were studied by GC-MS. Gas liquid chromatogram of New Coccine solution after chlorination is shown in Chart 3.

Large one peak appeared under low column temperature in this chart, while under high column temperature, no clear peaks appeared. The large peak was assumed to be chloroform by retention time of authentic sample, and confirmed from the mass spectrum. The result is shown in Fig. 4.
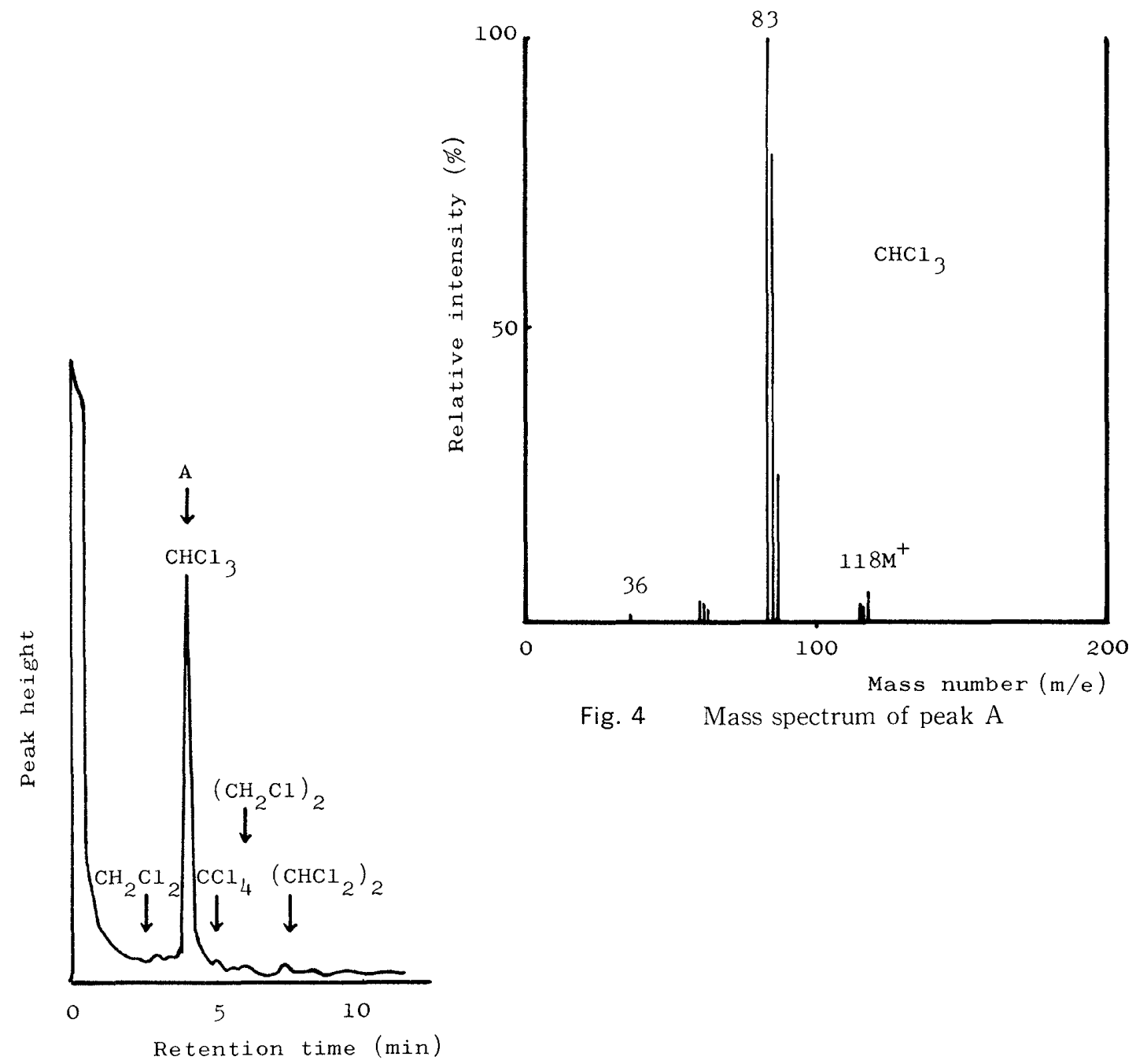

Fig. 4 Mass spectrum of peak A

Chart 3 Gas liquid chromatogram of New Coccine solution after chlorination

Column : 30\% silicone DC 550/celite 545

Temperature: column $-63^{\circ} \mathrm{C}$, Inj. $-75^{\circ} \mathrm{C}$

Flow rate: nitrogen $25 \mathrm{ml} / \mathrm{min}$. 
Formation of chloroform was compared with other several dyes under the most suitable condition, each dye was treated with $10 \mathrm{mg}$ of sodium hypochlorite and kept for 1 hr. These results are shown in Table 1 .

Table 1 Determination of chloroform in various dye solutions treated with sodium hypochlorite

\begin{tabular}{|c|c|c|}
\hline Coal-tar dye & $\begin{array}{l}\text { Dye added } \\
\text { (mM/tube) }\end{array}$ & $\begin{array}{c}\text { Formation of } \\
\text { chloroform } \\
\text { (mM/tube) }\end{array}$ \\
\hline Orange I & 2 & 0.88 \\
\hline Orange II & 11 & 0.80 \\
\hline Amaranth & "n & 0.76 \\
\hline Indigo Carmine & $\|$ & 0.85 \\
\hline Erythrosine & 11 & 1.04 \\
\hline Eosine & "l & 0.95 \\
\hline Phloxine & $n$ & 1.07 \\
\hline Rose Bengale & $n$ & 1.00 \\
\hline Acid Red & $n$ & 1.13 \\
\hline Light Green SF & $n$ & 1.25 \\
\hline Guinea Green B & 11 & 1.33 \\
\hline Acid Violet $6 \mathrm{~B}$ & 11 & 1.34 \\
\hline
\end{tabular}

Note 1) Amount of chloroform in dye solution was determined by gas chromatography.

Note 2) Sodium hypochlorite : $10 \mathrm{mg} /$ tube Reaction time : 1 hour

Chloroform was formed from all dyes, the amount of chloroform was $0.76-1.34 \mathrm{~mm} /$ tube (90-161 ppm ) from $2 \mathrm{mM}$ of dye. It must be noted that such ppm level of chloroform formed from dye is larger than usual ppb level of chloroform (33.8-106.5 ppb) formed from industrial waste water (Ishikawa et al., 1978).

TLm values (for $48 \mathrm{hrs}$ at $25^{\circ} \mathrm{C}$ ) of chloroform and its homologous compounds were determined. Dichloromethane, chloroform, carbon tetrachloride, dichloroethane and tetrachloroethane had TLm value of less than $10 \mathrm{mg} / \mathrm{L}$ exhibiting strong acute toxicity to fish.

\section{CONCLUSION}

Absorption of dye in fish body was studied. Partition coefficients (n-octanol/water) were determined on several dyes, and it was found that the larger the partition coefficient was, the stronger was the toxicity of the dye to fish on the whole. On the other hand, xanthene dyes showed another reason of toxicity, i. e. halogen atoms in their structures.

Since halogen liberated from dye under photo-irradiation exhibited strong toxicity to fish, mechanism of dehalogenation from mother compound was studied. It was found that the dyes in solution were in excited triplet state and halogen was liberated from the dye in 
free form. The amount of liberated halogen quite corresponded to the amount of deiodinated organic compound, 12, 13, 14,15- tetrachlorofluorescein sodium.

In order to study the safty of dye industrial effluent after chlorination, formation of organohalide compounds were studied by GC-MS spectra. Chloroform was formed by chlorination with sodium hypochlorite. The amount of chloroform was proportional to the concentration of chlorine and time of reaction.

Chloroform and its homologous compounds had TLm value of less than $10 \mathrm{mg} / \mathrm{L}$ ( 48 hrs at $25^{\circ} \mathrm{C}$ ) exhibiting strong acute toxicity to fish.

\section{REFERENCES}

Freed V. H., Chiou C. T., Haque R. (1977) : Chemodynamics, transport and behavior of chemicals in the environment-A problem in environmental health. Environmental Health Perspectives, $20,55-70$

Ishikawa T., Ose Y. and Sato T. (1978): Organohalides formation by chlorination of waste water. Proceeding of aquatic environment in Pacific region, Taipei, August, 21-23.

Japanese Industrial Standards Committee (1974): "Testing methods for industrial waste water" JIS K 0102, pp. 40.

Larson R.A. and Rockwell A. L. (1979): Chloroform and chloroform production by decarboxylation of natural acids during aqueous chlorination. Environmental Science \& Technology, 13, $325-329$.

Matsuura T. (1970): "Organic photochemisty", pp. 38. Kagaku Dohjin Co. Ltd.

Motonaka J. (1979): Potentiometric titrations of halide mixtures with an iodide-selective electrode. Analytica Chimica Acta, 105, 417--421.

Murphy K. L., Zaloum R. and Fulford D.(1975) : Effect of chlorination practice on soluble organics. Water Res., 9, 389-396.

Stary J. (1964): "The solvent extraction of metal chelates", pp. 5, Pergamon Press.

Sugiura K., Ito N., Matsumoto N., Mihara Y., Murata K., Tsukakoshi Y. and Goto M. (1978): Accumulation of polychlorinated biphenyls and polybrominated biphenyls in fish. Chemosphere, 9, 731-736.

Symons J. M., Bellar T. A., Carswell J. K., Demarko J., Kropp K. L., Robeck G. G., Seegar D. R., Slocum C. J., Smith B. L. and Stevens A. A. (1975): National organics reconnaissance survey for halogenated organics. J. American Water Works Association, 67, 634-647.

Tonogai Y., Iwaida M., Tati M., Ose Y. and Sato T. (1978): Biochemical decomposition of coaltar dyes II. Acute toxicity of coal-tar dyes and their decomposed products. J. Toxicol. Sci., 4, 205-214.

Tonogai Y., Ito Y., Iwaida M., Tati M., Ose Y. and Sato T.1979^): Studies on the toxicity of coaltar dyes. I. Photodecomposed products of four xanthene dyes and their acute toxicity to fish. J. Toxicol. Sci., 4, 115-126.

Tonogai Y., Ito Y., Iwaida M., Tati M., Ose Y. and Sato T.(1979 $)$ : Studies on the toxicity of coaltar dyes. II. Examination of the biological reaction of coal-tar dyes to vital body. J. Toxicol. Sci., 4, 211-220.

Japanese Industrial Standards Committee. (1975): "Testing method for industrial waste water" JIS K0102, pp 154-157. 